\title{
MULTI-OBJECTIVE OPTIMIZATION OF PROCESSING PARAMETERS IN WEDM WITH STAINLESS STEEL-304 FOR DIE- ANGULAR CUTTING
}

\author{
LE $\operatorname{Van} S y^{1,2}$ \\ ${ }^{1}$ PetroVietnam Manpower Training College (PVMTC) \\ 120, Tran Phu, Ward 5, Vung Tau City, Vietnam, \\ e-mail:sylv@pvmtc.edu.vn \\ ${ }^{2}$ PetroVietnam University (PVU) \\ 672, CMT-8, Long Toan, Ba Ria City, Vietnam, \\ e-mail:sylv@pvu.edu.vn
}

\begin{abstract}
This paper is focusing on the improvement of the accuracy of WEDM process for machining the precision-die angular stainless-steel parts. The controllable parameters are studied and analyzed by using Response Surface Method technique with respect to the responses of dimensional accuracy and surface quality. Then, these models are optimized by using the multi-objective optimization technique to realize optimal processing parameters. These optimal controllable parameters are ready for WEDM operating technicians' use.
\end{abstract}

KEYWORDS: WEDM, stainless steel, die, CNC, Electrical discharge machining, Response Surface Method.

\section{Introduction}

Electrical discharge machining (EDM) has become a potential non-conventional machining technique for very hard conductive materials which are difficult to machine by using conventional processes. This process is based on the sparking phenomenon between the tooling electrode and the workpiece to erode the material of the workpiece. The tooling electrode and the workpiece are separated by a stream of dielectric fluid or the workpiece is submerged in the dielectric tank to promote temperature stabilization, efficient flushing and remove the containments produced from eroding the material. Wire electrical discharge machining (WEDM) evolved from EDM technique by replacing the traditional electrode with a continuously travelling wire electrode which is the best suitable for machining precise stamping and extrusion tools and dies and medical parts with high dimensional accuracy and surface quality. The accuracy degree and efficiency of this process depend on the number of uncontrollable and controllable parameters and responses. Many efforts have been made in the decades to improve the applicability of WEDM machines to meet the increasing demands of high surface quality and complex-shape products [1]. The studies were focused on three major areas: 1) optimizing processing parameters; 2) Monitoring and controlling the WEDM process; 3) developing WEDM machines to mature the capacity of WEDM technique for machining the products which have complex and sharp geometry and made of very hard materials. One of the important tasks needing to deeply study is the optimization of processing parameters for multi objectives (responses) such as material removal rate, surface quality, or dimensional accuracy $[10,15]$. It is clear that the machining performance of WEDM is a complex and stochastic process which depends on many parameters. A single processing parameter change will affect the machining performance in a complex way. Thus, 
identifying optimal processing parameters for practical requirements is extremely difficult for WEDM operators, even for experienced ones. In the literature, several attempts have been made at investigating the influence of processing parameters (such as pulse on/off time, peak current and gap voltage, servo voltage and servo feed rate, dielectric flow rate, wire speed or wire feed, wire tension, and wire type) on different process responses (such as material removal rate, surface roughness, and dimensional accuracy) and identifying optimal machining factors from their finite combinations $[1,2,3,16]$.

Selvakumarv et. al. [2] and Khadar [14] used Taguchi methodology to study the influence of both machine controllable factors (wire tension, pulse-on time, pulse frequency, peak current and servo voltage) and machine uncontrollable factors (flushing nozzle height, workpiece thickness and corner angle) on material removal rate, surface roughness and corner error for machining Monel 400 alloy. The authors analyzed the impact of pulse parameters modification in corner accuracy improvement and used Taguchi's additive model predictions and Pareto optimality approach.

Sanchez et. al. [4] studied the accuracy of corner geometry generated by successive cuts (roughing and finishing) and identified the errors at different zones of the corner which related to the removed material during each cut. The authors also discussed the influence of machining parameters such as work thickness, corner radius and the number of trim cuts and noticed that the errors generated by the previous cuts should be considered in a corner accuracy optimization procedure. Hsue et. al. [5] also built a model which can identify the rate of the removed material in corner cutting by using a fundamental geometry analysis. Han et al. [6] proposed a control method to improve the corner machining accuracy in rough cutting and implemented a FEM simulation method. The authors also proposed a corner error simulation method to predict the accuracy of the actual corner profile under different cutting conditions.

Zhi Chen et. al. [7] performed a study to improve the geometrical accuracy of rough corner cutting with different angles $\left(45^{\circ}, 90^{\circ}\right.$, and $135^{\circ}$ angle). The authors also applied Taguchi approach to identify the main effect of controllable factors on corner error and proposed an elliptic fitting method to present the trajectory of the wire electrode center. It is concluded that the corner error is decreased more than $50 \%$ in rough corner cutting (at $5 \mathrm{~mm} / \mathrm{min}$ cutting feedrate) by using the optimized control factors combination.

Yan and Huang [8] improved machining accuracy by designing a closed loop wire tension control system which reduced 50\% corner-error and significantly improved the vertical straightness. Lin et al. [9] proposed a control strategy based on fuzzy logic to improve the corner machining accuracy in which more than 50\% the accuracy of the corner machining can be improved while the machining time is not higher than $10 \%$ of the normal machining process.

In general, most studies investigated the selection of machining parameters for both rough and finishing operations in WEDM by using the regression method. The best combination of process parameters for the optimal machining performance involves analytical and statistical methods. The optimization of the WEDM process is a difficult task because of the complex and random nature of the erosion process which requires the application of deterministic as well as stochastic techniques $[10,11,12,13,16]$. In this paper, controllable parameters such as wire tension, wire speed, pulse on/off time, peak current are investigated to analyze their influence on both dimensional accuracy and surface quality in machining a die-angular model. Then, these models are optimized by using multi-objective optimization technique to realize optimal processing parameters for machining stainless steel (grade 304) products. These optimal controllable parameters are ready for WEDM operators' use. 


\section{$2 \quad$ Material and Experimental Design}

\subsection{Material properties}

a)
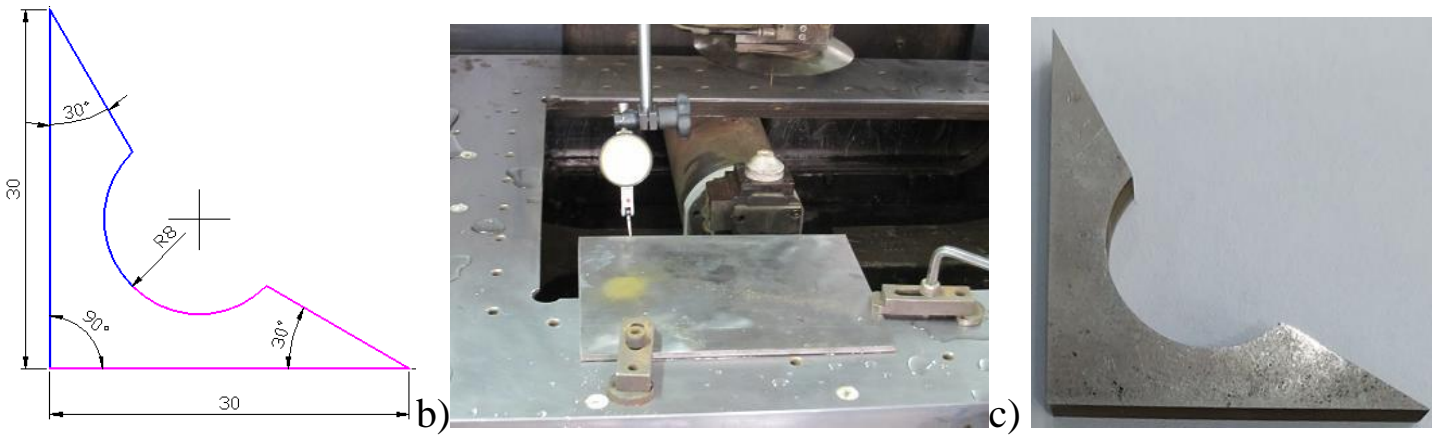

Fig. 1 Experimental specimen; a) CAD profile; b) Machining setup; c) Finished part

In order to study the influence of processing parameters on the accuracy of corner cutting by WEDM, a profile of the experimental model which has different angles and intersections with the circular arc is shown in Fig. 1. The accuracy and surface roughness of the corner angles of $30^{\circ}$ and $90^{\circ}$ and the circular curve have been considered with respect to different sets of processing parameters. The experimental model is cut from the plate of AISI304 material $(0.08 \% \mathrm{C}, 18 \% \mathrm{Cr}, 2 \% \mathrm{Mn}, 1 \% \mathrm{Si}, 8 \% \mathrm{Ni}, 0.045 \% \mathrm{P}$, and $0.03 \% \mathrm{~S})$ with thickness of $5 \mathrm{~mm}$. This material possesses excellent corrosion resistance, toughness and cryogenic properties which are commonly used in many industrial applications, such as chemical, pharmacy, and food industries. The conventional machining for AISI304 alloy is relatively difficult for high precision products with sharp edges and circular curves. Studying optimal machining parameters for WEDM machining approach is one of the important tasks for manufacturing products with complex shapes and very high precision.

The experiment models were cut by using FA20S high precision 5-axis CNC WEDM machine which is fabricated by Mitsubishi Company, Japan. The cutting wire is AC Brass LP1000 with diameter of $0.25 \mathrm{~mm}$ which is only used for a single round. The dielectric (distilled water) with conductivity of 20 mho kept at $25^{\circ} \mathrm{C}$ is flushed at $2.5 \mathrm{~kg} / \mathrm{cm}^{2}$. After being cut with each set of processing parameters, each model is investigated in terms of the profile accuracy and the surface roughness of the cutting edge by using 3D-Smart-CMM and Surtronic Duo machines.

\subsection{Design Matrix}

Table 1. Levels of processing parameters

\begin{tabular}{|l|c|c|c|c|}
\hline \multirow{2}{*}{ Parameters } & \multirow{2}{*}{ Code } & \multicolumn{3}{|c|}{ Level of value } \\
\cline { 3 - 5 } & & -1 & 0 & +1 \\
\hline Discharge current (IP) & $\mathrm{x}_{1}$ & 5 & 7 & 9 \\
\hline Pulse frequency (OFF) & $\mathrm{x}_{2}$ & 2 & 3 & 4 \\
\hline Wire speed (WS) & $\mathrm{x}_{3}$ & 6 & 8 & 10 \\
\hline Wire tension (WT) & $\mathrm{x}_{4}$ & 7 & 8 & 9 \\
\hline
\end{tabular}

The processing parameters considered in this study are presented in Table 1. The parameters and their value levels were chosen through review of previous studies, capacity of the machine, and experience. The experimental strategy is conducted according to the Response Surface Method which can investigate the influence of input parameters on the responses (Table 2). The geometric accuracy of the finished profile and surface quality are two important responses measured for regression analysis. Each experiment is repeated two times to ensure the accuracy of regression analysis. The geometric accuracy was measured 
directly from 3D-Smart-CMM machine and the surface roughness (Ra) was measured by Surtronic Duo machine.

Table 2. Design Matrix of Experiments

\begin{tabular}{|c|c|c|c|c|c|c|c|c|c|}
\hline \multirow{2}{*}{ Run } & \multicolumn{4}{|c|}{ Parameters } & \multirow{2}{*}{ Run } & \multicolumn{4}{c|}{ Parameters } \\
\cline { 9 - 11 } & & & & & & IP & OFF & WS & WT \\
\hline 1 & 0 & 0 & 0 & 0 & 11 & 0 & 0 & 0 & 0 \\
\hline 2 & 1 & 1 & 1 & -1 & 12 & 0 & $\mathrm{a}$ & 0 & 0 \\
\hline 3 & -1 & 1 & 1 & 1 & 13 & -1 & -1 & 1 & -1 \\
\hline 4 & 0 & $-\mathrm{a}$ & 0 & 0 & 14 & 0 & 0 & $-\mathrm{a}$ & 0 \\
\hline 5 & 0 & 0 & $\mathrm{a}$ & 0 & 15 & 1 & 1 & -1 & -1 \\
\hline 6 & $\mathrm{a}$ & 0 & 0 & 0 & 16 & 1 & -1 & 1 & 1 \\
\hline 7 & 1 & -1 & -1 & 1 & 17 & 0 & 0 & 0 & 0 \\
\hline 8 & 0 & 0 & 0 & 0 & 18 & $-\mathrm{a}$ & 0 & 0 & 0 \\
\hline 9 & 0 & 0 & 0 & $\mathrm{a}$ & 19 & 0 & 0 & 0 & $-\mathrm{a}$ \\
\hline 10 & -1 & -1 & -1 & -1 & 20 & -1 & 1 & -1 & 1 \\
\hline & & & & & 21 & 0 & 0 & 0 & 0 \\
\hline
\end{tabular}

\section{Statistical analysis of variance (ANOVA) and Discussion}

\subsection{Statistical analysis of variance (ANOVA)}

The surface roughness and geometric accuracy at $30^{\circ}$ and $90^{\circ}$ corners and the circular arc were measured by using Surtronic Duo and 3D-Smart-CMM machines as shown in Fig. 2. These values are shown in Table 2 used for ANOVA analysis. In this study, both two responses have the same optimum targets, the lower surface roughness and less corner errors are the indication of better performance. They are selected from ANOVA analysis to determine the relative significance of different factors. All ANOVA analyses are shown in Table 3. They describe the main effect of machining parameters on their responses. Generally, they show that P-values are very low, which demonstrate that the analyzed parameters are relevant to the process and this model has a fairly good fit. Moreover, the correlation coefficient $R^{2}$ and adjusted $R_{a d j}^{2}$ values of three responses $\left(R^{2}>98 \%\right.$ and $\left.R_{a d j}^{2}>93 \%\right)$ for accuracy of this model are very satisfactory.
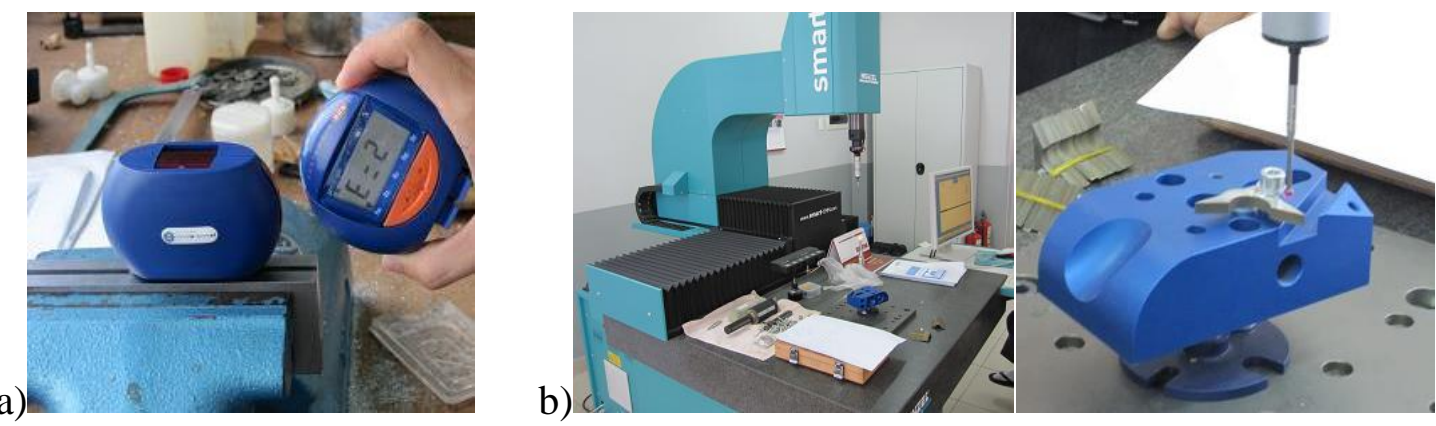

Fig. 2 a) Measurement of surface roughness; b) Measurement of geometric accuracy

Table 3. Model summary statistics for surface roughness

\begin{tabular}{|l|r|l|r|}
\hline Std. Dev. & 0.0641 & R $^{\mathbf{2}}$ & 0.9778 \\
\hline Mean & 3.74 & Adjusted R $^{\mathbf{2}}$ & 0.9261 \\
\hline C.V. \% & 1.72 & Predicted R $^{\mathbf{2}}$ & -1.1237 \\
\hline & & Adeq Precision & 17.3035 \\
\hline
\end{tabular}


Table 4. ANOVA for the responses

\begin{tabular}{|l|c|c|c|c|c||c|c|c|c|c|c|}
\hline \multicolumn{9}{|c||}{ Ra } & \multicolumn{9}{|c|}{ A-30 $^{\mathbf{0}}$} \\
\hline Source & SS & DOF & MS & F-value & \% & Source & SS & DOF & MS & F-value & \% \\
\hline A-IP & 0.0265 & 1 & 0.026 & 0.32 & 0.37 & A-IP & 0.0001 & 1 & 0.0001 & 35.21 & 33.33 \\
\hline B-OFF & 2.52 & 1 & 2.92 & 31.34 & 35.44 & B-OFF & $2.019 \mathrm{e}-06$ & 1 & $2.019 \mathrm{e}-06$ & 0.9808 & 0.67 \\
\hline C-WS & 2.599 & 1 & 2.59 & 32.32 & 36.55 & C-WS & 0.0000 & 1 & 0.0000 & 17.98 & 0 \\
\hline D-WT & 0.02 & 1 & 0.02 & 0.24 & 0.28 & D-WT & $7.703 \mathrm{e}-06$ & 1 & $7.703 \mathrm{e}-06$ & 3.74 & 2.56 \\
\hline $\mathbf{A B}$ & 0.0014 & 1 & 0.0014 & 0.017 & 0.019 & AB & 0.0000 & 1 & 0.0000 & 12.21 & 0 \\
\hline AC & 0.1984 & 1 & 0.198 & 2.43 & 2.79 & AC & 0.0000 & 1 & 0.0000 & 20.87 & 0 \\
\hline AD & 0.0234 & 1 & 0.023 & 0.28 & 0.32 & AD & $6.290 \mathrm{e}-06$ & 1 & $6.290 \mathrm{e}-06$ & 3.06 & 2.096 \\
\hline BC & 0.0032 & 1 & 0.003 & 0.039 & 0.045 & BC & $6.860 \mathrm{e}-06$ & 1 & $6.860 \mathrm{e}-06$ & 3.33 & 2.28 \\
\hline BD & 1.71 & 1 & 1.71 & 20.92 & 24.05 & BD & 0.0001 & 1 & 0.0001 & 29.14 & 33.33 \\
\hline CD & 0.018 & 1 & 0.018 & 0.22 & 0.25 & CD & $1.293 \mathrm{e}-07$ & 1 & $1.293 \mathrm{e}-07$ & 0.0628 & 0.04 \\
\hline Error & 0.0015 & 4 & 0.0004 & & & Error & $1.106 \mathrm{e}-06$ & 4 & $2.766 \mathrm{e}-07$ & & \\
\hline Total & 7.11 & 20 & & & & Total & 0.0003 & 20 & & & \\
\hline
\end{tabular}

\begin{tabular}{|c|c|c|c|c|c||l|c|c|c|c|c|}
\hline \multicolumn{9}{|c|}{$\mathbf{A - 9 0}^{\mathbf{0}}$} & \multicolumn{10}{|c|}{ R-8 } \\
\hline Source & SS & DOF & MS & F-value & \% & Source & SS & DOF & MS & F-value & \% \\
\hline A-IP & 0.0001 & 1 & 0.0001 & 36.83 & 7.14 & A-IP & 0.0005 & 1 & 0.0005 & 71.43 & 41.67 \\
\hline B-OFF & 0.0008 & 1 & 0.0008 & 348.68 & 57.14 & B-OFF & 0.0000 & 1 & 0.0000 & 1.74 & 0 \\
\hline C-WS & $2.364 \mathrm{e}-06$ & 1 & $2.364 \mathrm{e}-06$ & 1.03 & 0.16 & C-WS & $8.062 \mathrm{e}-07$ & 1 & $8.062 \mathrm{e}-07$ & 0.11 & 0.067 \\
\hline D-WT & $5.000 \mathrm{e}-07$ & 1 & $5.000 \mathrm{e}-07$ & 0.21 & 0.035 & D-WT & $5.000 \mathrm{e}-07$ & 1 & $5.000 \mathrm{e}-07$ & 0.069 & 0.041 \\
\hline AB & $2.929 \mathrm{e}-07$ & 1 & $2.929 \mathrm{e}-07$ & 0.12 & 0.02 & AB & $4.554 \mathrm{e}-06$ & 1 & $4.554 \mathrm{E}-06$ & 0.63 & 0.37 \\
\hline AC & 0.0000 & 1 & 0.0000 & 7.85 & 0 & AC & $1.125 \mathrm{e}-06$ & 1 & $1.125 \mathrm{e}-06$ & 0.16 & 0.09 \\
\hline AD & 0.0005 & 1 & 0.0005 & 221.79 & 35.71 & AD & $4.120 \mathrm{e}-08$ & 1 & $4.120 \mathrm{e}-08$ & 0.0057 & 0.003 \\
\hline BC & $8.000 \mathrm{e}-06$ & 1 & $8.000 \mathrm{e}-06$ & 3.49 & 0.57 & BC & 0.0000 & 1 & 0.0000 & 5.04 & 0 \\
\hline BD & 0.0001 & 1 & 0.0001 & 41.57 & 7.14 & BD & 0.0005 & 1 & 0.0005 & 65.34 & 41.67 \\
\hline CD & 0.0000 & 1 & 0.0000 & 7.85 & 0 & CD & 0.0001 & 1 & 0.0001 & 7.69 & 8.33 \\
\hline Error & $8.800 \mathrm{e}-06$ & 4 & $2.200 \mathrm{e}-06$ & & & Error & $8.480 \mathrm{e}-07$ & 4 & $2.120 \mathrm{e}-07$ & & \\
\hline Total & 0.0014 & 20 & & & & Total & 0.0012 & 20 & & & \\
\hline
\end{tabular}
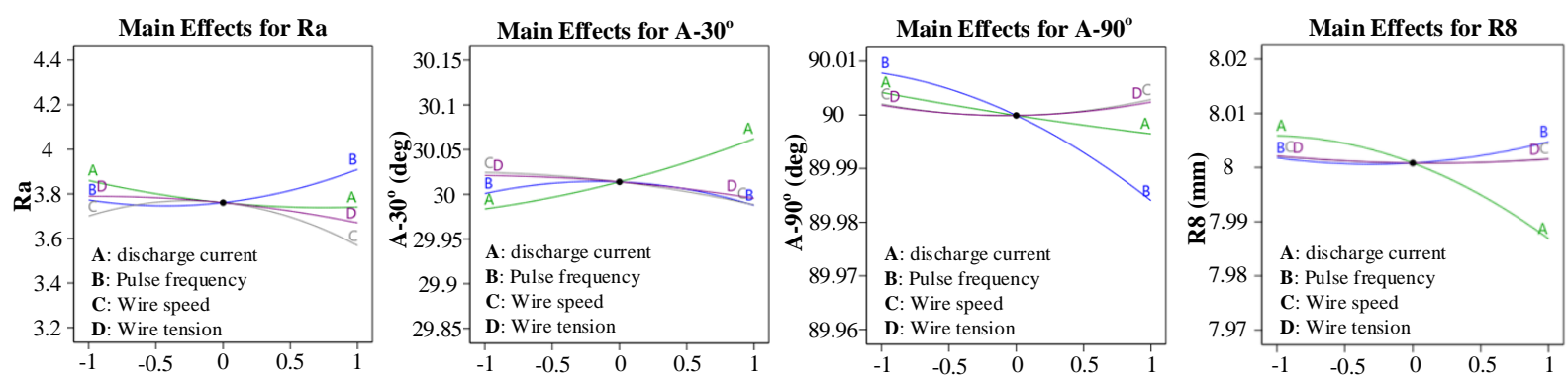

Fig. 3 Effect of main factors
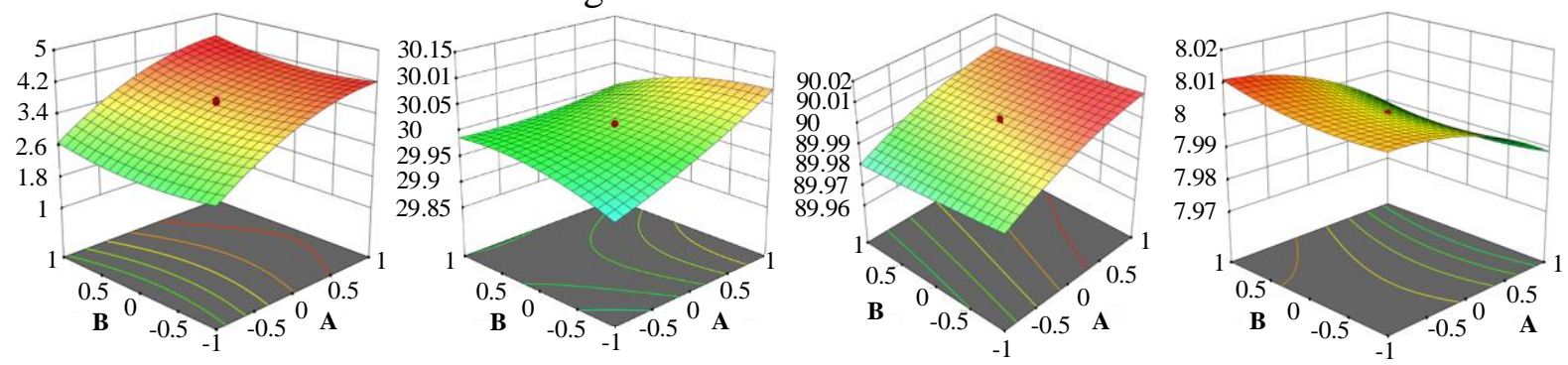

Fig. 4 Interaction effect of machining parameters

From Table 4, it is observed that pulse frequency and wire speed are the main factors which affect significantly the surface roughness with high percentage contributions of $35,4 \%$ and $36.5 \%$, respectively. With an increase of pulse frequency, the quality of machining 
surface shows a decreasing trend because it requires greater energy of discharges which produces a great depth of crater and overcut. The discharge current has less effect on the surface roughness because this factor plays an important role in the material removal rate rather than the surface roughness (Fig. 3). The wire speed and wire tension have significant contributions to the surface roughness. High wire tension and wire speed will avoid wire vibration and wire lag in the WEDM process. Moreover, the interaction effect of high wire tension with high pulse frequency trigger off wire breakage. Their interaction contribution is about $24.05 \%$. The remaining parameters with percentage contributions of less than $10 \%$ do not have much effect in the statistics.
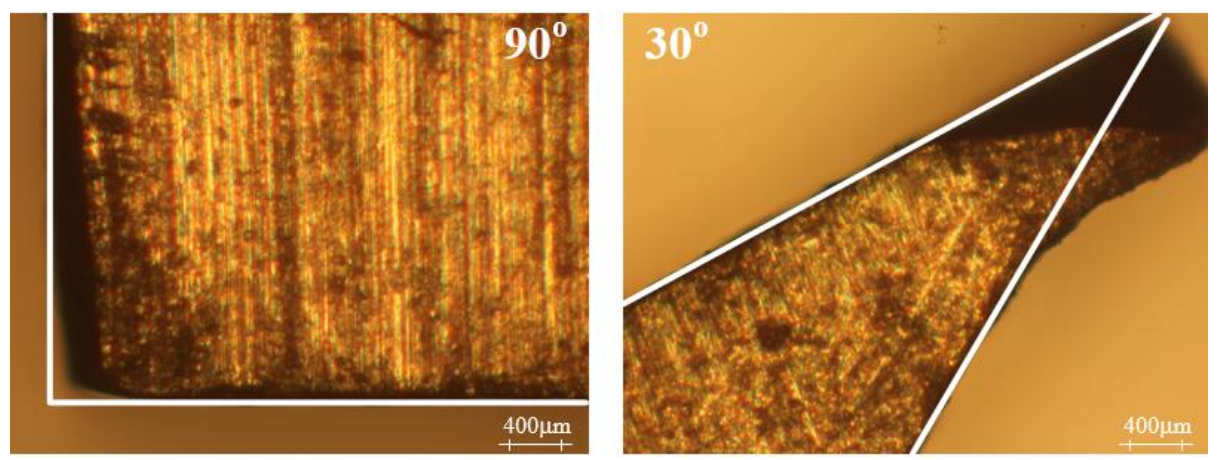

Fig. 5 Angle error of $90 \mathrm{o}$ and $30 \mathrm{o}$

For geometric accuracy of corners, it is observed that the discharge current and pulse frequency have opposite effect for $30^{\circ}$ corner, arc of R8 and $90^{\circ}$ corner (Fig. 3). The high discharge current produces high energy which triggers off the melting and vaporization of the larger workpiece material. Hence, it can create geometric error at the corner and the intersection area between the arc and straight profiles. The corner with more acute angular has significant effect on the geometric accuracy in the WEDM process (with percentage contribution of $33.33 \%$ ). Therefore, it is obvious that increasing discharge current intensity at the acute corner will not result in high corner accuracy, especially during a machining process with high thickness job and high wire speed. The higher discharge energy leads to a greater depth of crater and overcut (Fig. 5). Therefore, the geometric accuracy in the corner machining process is improved in the case of higher corners. It is also interesting to show that the wire speed and wire tension have less effect on the geometric accuracy for machining $90^{\circ}$ corner. However, they have a decreasing trend in geometric accuracy for machining parts with $30^{\circ}$ corner and arc corner (Fig. 3). Therefore, this should be especially noted in practice to avoid increasing these parameters for machining acute corners and complex profiles. The machining time can be reduced significantly in the case of increasing the discharge current to achieve better corner accuracy in larger corners.

\subsection{Multi-response optimization}

To evaluate the influence of machining parameters in the WEDM process on both surface roughness and geometric accuracy, a multi-response optimization with the-smaller-the-better model is used here [14]. This model is a simple and efficient method to identify optimum or near optimum factors of design parameters. Following the DOE method, smaller values of surface roughness and geometric accuracy indicate better machining performance (i.e., thesmaller-the-better). The multiple response method is determined through an objective function of $\mathrm{D}(\mathrm{X})$ called the desirability function. This function reflects the desirable ranges for each response $\left(d_{i}\right)$ which are from zero (the least desirable) to one (the most desirable). The simultaneous objective function is a geometric mean of all transformed responses: 


$$
D=\left(d_{1} \cdot d_{2} \cdot \ldots \cdot d_{n}\right)^{1 / n}=\left(\prod_{i=1}^{n} d_{i}\right)^{1 / n}
$$

where $n$ is the number of responses in the analysis process. Each response must have a low and high value assigned to each goal. As mentioned above, the responses of surface roughness and angle accuracy are the-smaller-the-better (e.g., minimum) in each desirability range. If any of the responses or factors falls outside their desirability range, the overall function becomes zero. Fortunately, two responses have the same goals, therefore, all goals get combined into one desirability function. The desirability is an objective function that ranges from zero outside of the limits to one at the goal. The numerical multi-response optimization finds a point that maximizes the desirability function. The maximum points for each response with discharge current (IP) and pulse frequency (OFF) are shown in Fig. 6. The list of machining parameters from the final optimizing process with desirability in the descending order is shown in Table 5. The maximum desirability of 0.734 is considered as the optimum result for the multi-response optimization with the-smaller-the-better responses. This table is useful for practical engineers to select machining parameters that satisfy the requirements of surface roughness and corner error.

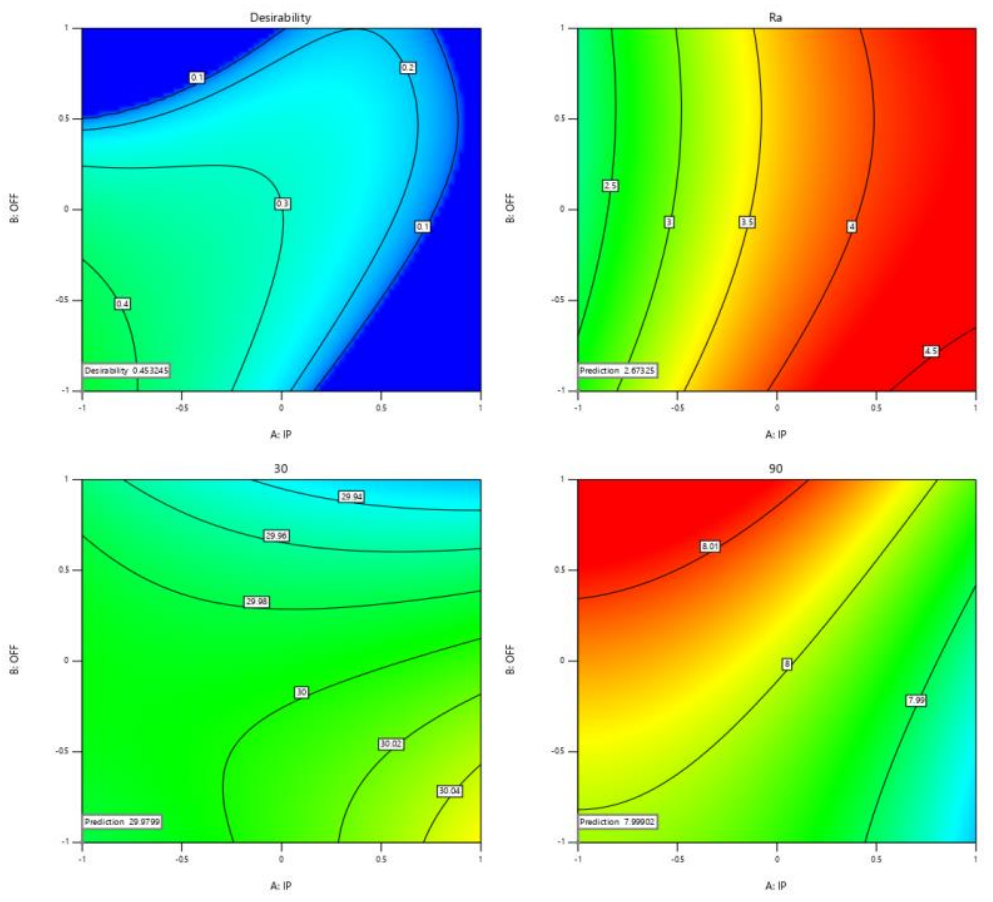

Fig. 6 Distribution of desirability and responses

Table 5. Solutions of multi-response optimization

\begin{tabular}{|r|c|c|c|c|c|c|c|c|r|r|}
\hline Number & IP & OFF & WS & WT & Ra & A30 & A90 & R8 & Desirability & \\
\hline $\mathbf{1}$ & $\mathbf{0 . 9 9 9}$ & $\mathbf{1 . 0 0 0}$ & $\mathbf{0 . 9 9 9}$ & $\mathbf{1 . 0 0 0}$ & $\mathbf{3 . 4 9 9}$ & $\mathbf{2 9 . 9 8 9}$ & $\mathbf{8 9 . 9 7 0}$ & $\mathbf{7 . 9 8 4}$ & $\mathbf{0 . 7 3 4}$ & Selected \\
\hline 2 & 1.000 & 1.000 & 1.000 & 0.986 & 3.505 & 29.989 & 89.970 & 7.984 & 0.733 & \\
\hline 3 & 0.995 & 1.000 & 0.974 & 1.000 & 3.503 & 29.991 & 89.969 & 7.984 & 0.732 & \\
\hline 4 & 0.995 & 1.000 & 0.964 & 1.000 & 3.505 & 29.992 & 89.969 & 7.984 & 0.731 & \\
\hline 5 & 1.000 & 1.000 & 0.974 & 0.986 & 3.509 & 29.991 & 89.970 & 7.984 & 0.731 & \\
\hline 6 & 0.997 & 1.000 & 0.987 & 0.979 & 3.509 & 29.989 & 89.970 & 7.984 & 0.730 & \\
\hline 7 & 0.998 & 0.992 & 1.000 & 0.970 & 3.510 & 29.989 & 89.970 & 7.984 & 0.728 & \\
\hline 8 & 0.959 & 0.999 & 1.000 & 1.000 & 3.494 & 29.989 & 89.970 & 7.985 & 0.728 & \\
\hline 9 & 0.951 & 1.000 & 1.000 & 1.000 & 3.493 & 29.989 & 89.970 & 7.985 & 0.727 & \\
\hline 10 & 0.999 & 1.000 & 1.000 & 0.951 & 3.519 & 29.988 & 89.970 & 7.984 & 0.727 & \\
\hline
\end{tabular}

Volume 71, No. 2, (2021) 


\subsection{Verification of experiments}

The final step is to verify the results of the multi-response optimization process. The selected optimum parameters are used to verify the improvement of surface roughness and corner accuracy. The predicted results in the multi-response optimization process were compared directly with the actual machining results. A good agreement was obtained between these compared results (Fig. 7). From measurement of the specimens machined with the optimal parameters, it shows a decreasing trend of 1.31 times for surface roughness and 1.24 times for corner error (Figures 7 and 8). The scanning electron microscope (SEM) presented in Fig. 8 shows the quality of machining surface before and after carrying out the multiresponse optimization. These results confirm the effectiveness of the multi-response optimization for the WEDM process. The machining performance was improved significantly with the optimal machining parameters.
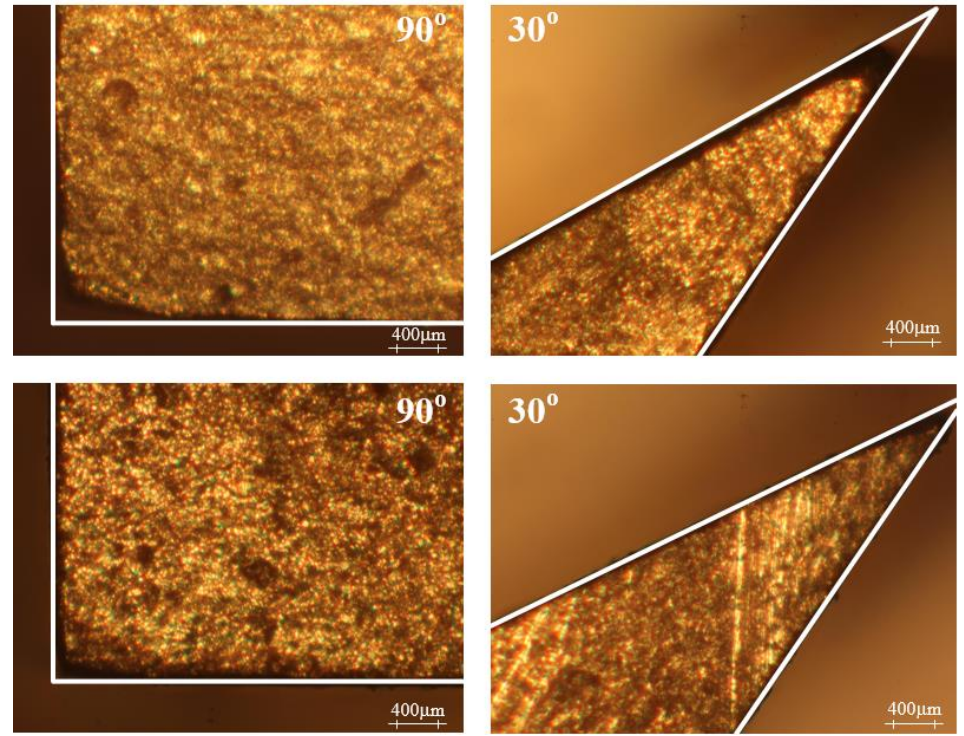

Fig. 7 Verification of angle error before and after optimization
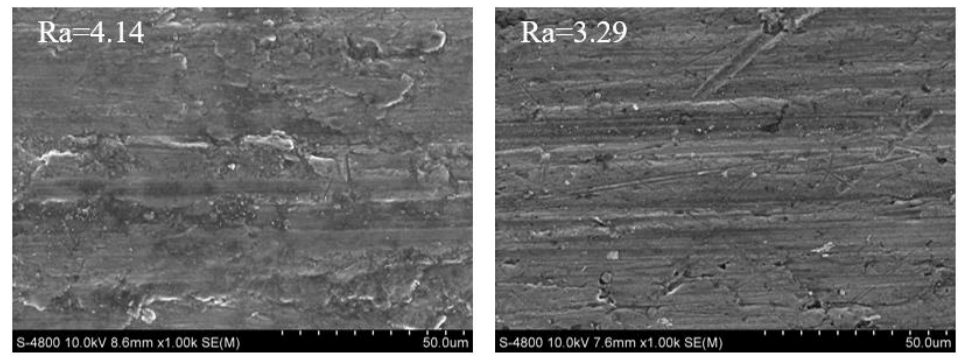

Fig. 8 SEM images before and after optimization

\section{CONCLUSION}

This study performed the multi-objective optimization of the WEDM process using the Surface Respond Method. The applicability of this procedure for optimizing machining parameters for die-angular parts is very simple and efficient. The effect of machining parameters on surface roughness and corner error were identified and understood deeply. The study results can help operating engineers select optimal machining parameters with respect to the required levels of surface roughness and geometric accuracy of the corner. Pulse frequency and wire speed are the main parameters that have significant effect on the quality of the machining surface. Moreover, the experiments show high interaction effect of wire tension and pulse frequency on the surface roughness and the wire strength in the WEDM 
operation. While the discharge current and pulse frequency have significant effect on the geometric accuracy of the acute corner, the affecting level was decreased in machining the larger corners or arcs. The wire speed and wire tension also affect the geometric accuracy of the larger corners; however, such effect have a decreasing trend for machining parts with smaller corners and arc corners. The list of optimal machining parameters for WEDM operation relating to different levels of the machining part are extracted and verified from actual experiments in this study.

\section{REFERENCES}

[1] Ho, K.H, Newman, S.T, Rahimifard, S., Allen, R. D. "State of the art in wire electrical discharge machining (WEDM)", International Journal of Machine Tools and Manufacture 44 (12-13), pp. 1247 - 1259, 2004.

[2] Selvakumar, G, Thiruppathi, K. K, Selvaraj, M, Manohar, J. "Enhancing die corner accuracy using path modification strategy in wire electrical discharge machining of Monel 400", Proceedings of the Institution of Mechanical Engineers, Part C: Journal of Mechanical Engineering Science 232 - 2, pp. 207 - 216, 2018.

[3] Anshuman K., Kumar A., Vivekananda, K., Maity, KP. "Effect of wire electrode materials on die-corner accuracy for Wire Electrical Discharge Machining (WEDM) of Inconel 718”, Materials Today: Proceedings 5-5 (2), pp. 12641 - 12648, 2018.

[4] Sanchez, J.A., Plaza, S., Ortega, N., Marcos, M., Albizuri, J. "Experimental and numerical study of angular error in wire-EDM taper-cutting", International Journal of Machine Tools and Manufacture 48 (12 - 13), pp. 1420 - 1428, 2008.

[5] Hsue W. J., Liao, Y. S., Lu, S. S. "Fundamental geometry analysis of wire electrical discharge machining in corner cutting", International Journal of Machine Tools and Manufacture 39 (4), pp. 651 - 667, 1999.

[6] Han, F., Zhang, J., Soichiro, I. "Corner error simulation of rough cutting in wire EDM", Precision Engineering 31 (4), pp. 331 - 336, 2007.

[7] Chen, Z., Huang, Y., Zhang, Z. et al. "An analysis and optimization of the geometrical inaccuracy in WEDM rough corner cutting”, Int J Adv Manuf Technol 74, pp. 917 929, 2014.

[8] Mu-Tian Yan, Pin-Hsum Huang "Accuracy improvement of wire-EDM by real-time wire tension control", International Journal of Machine Tools and Manufacture, 44 (7 8), pp. $807-814,2004$.

[9] Chin-Teng Lin, I-Fang Chung, Shih-Yu Huang "Improvement of machining accuracy by fuzzy logic at corner parts for wire-EDM", Fuzzy Sets and Systems 122 (3), 499 $511,2001$.

[10] Sadananda C., Souren M., Dipankar B. "An investigation on dimensional accuracy and surface topography in powder mixed WEDM using RSM and GRA-PCA", Materials Today: Proceedings 44 (1), pp. 524 - 1530, 2021.

[11] Kashif, I., Sadaf, Zr., Sarmad, A. K., Mudassar, R., Abdullah, A., Saqib, A., "Minimizing the corner errors (top and bottom) at optimized cutting rate and surface finish during WEDM of Al6061", Engineering Science and Technology an International Journal 24 (4), pp. 1027 - 1041, 2021. 
[12] Arunbharathi, R., Ashoka, V. P., Jayasuryaa, J., Pranav, K., Harsha, V. N. "Optimization of WEDM process parameters for D3 die steel using RSM", Materials Today: Proceedings 37 (2), pp. 2063 - 2069, 2021.

[13] Zhi Chen, Hongbing Zhou, Zhaojun Yan, Fenglin Han, Hongzhi Yan "A new highspeed observation system for evaluating the spark location in WEDM of Inconel 718", Journal of Materials Research and Technology 13, pp. 184 - 196, 2021.

[14] Khadar, Basha Shaik, Jagannadha, Raju M. V. and Murahari, Kolli. "Multi-Objective Optimization of Process Parameters for Powder Mixed Electrical Discharge Machining of Inconel X-750 Alloy Using Taguchi-Topsis Approach”, Strojnícky časopis - Journal of Mechanical Engineering 71 (1), pp. 1 - 18, 2021. DOI: 10.2478/scjme-2021-0001

[15] Dwaipayan, De, Titas, Nandi and Asish, Bandyopadhyay "Parametric Study for Wire Cut Electrical Discharge Machining of Sintered Titanium”, Strojnícky časopis - Journal of Mechanical Engineering 69 (1), pp.17 - 38, 2019. DOI: 10.2478/scjme-2019-0002

[16] Himanshu, Prasad Raturi, Lalta, Prasad, Mayank, Pokhriyal and Vineet, Tirth. "An Estimating the Effect of Process Parameters on Metal Removal Rate and Surface Roughness in WEDM of Composite Al6063/SiC/AlO by Taguchi Method", Strojnícky časopis - Journal of Mechanical Engineering 67 (2), pp. 25 - 36, 2017. DOI: 10.1515/scjme-2017-0015 